\title{
Toxoplasmosis Sistémica en un Canguro Rojo (Macropus rufus) Cautivo
}

\author{
Systemic Toxoplamosis in a Captive Red Kangaroo (Macropus rufus) \\ "Ochoa-Amaya, J. E.; " Ciuoderis-Aponte, K. A.; ${ }^{* * *}$ A. Lim; ${ }^{* * *}$ S. Bolin \& ${ }^{* * *}$ Langohr, I.
}

OCHOA-AMAYA, J. E.; CIUODERIS-APONTE, K. A.; LIM, A.; BOLIN, S. \& LANGOHR, I. Toxoplasmosis sistémica en un canguro rojo (Macropus rufus) cautivo. Int. J. Morphol., 30(1):70-76, 2012.

RESUMEN: Los objetivos del estudio fueron presentar y documentar los hallazgos histopatológicos de toxoplasmosis sistémica en un canguro rojo (Macropus rufus) mantenido en cautiverio donde se describen los hallazgos macro y microscópicos encontrados y los análisis adicionales realizados. En el laboratorio de histopatología animal (Universidad de los Llanos) se recibieron muestras de tejidos fijados en formol tamponado, al 10\% que procedían de un ejemplar macho de Macropus rufus, de ocho años de edad y $50 \mathrm{~kg}$ de peso corporal. Las muestras se procesaron mediante métodos rutinarios para microscopía óptica. Los cortes histológicos de 3-4 mm de grosor se colorearon con Hematoxilina-Eosina (H\&E) y se realizó en algunos cortes la tinción de Ácido Periódico Schiff (PAS), PCR e IHQ. Al análisis histopatológico se encontró una toxoplasmosis sistémica asociada a quistes de protozoarios con inmunoreactividad positiva para T. gondii. La detección de $T$ gondii en tejidos en formalina fue hecha usando dos ensayos de PCR que señalaban segmentos de ADN de diferentes secuencias repetitivas encontradas en $T$ gondii y la IHQ confirmo lo hallado por PCR. Histopatológicamente se diagnosticó infección crónica por protozoarios eucoccideos de la familia Sarcocystidae. El diagnóstico etiológico fue de toxoplasmosis.

PALABRAS CLAVE: Canguro; Toxoplasmosis; Taquizoitos; Bradizoitos.

\section{INTRODUCCIÓN}

Las especies de protozoos pertenecientes a la familia Sarcocystidae del orden Eucoccida y filo Apicomplexa se caracterizan por tener un ciclo heteroxeno facultativo que además del parasitismo enteroepitelial presentan formas multiplicativas o zoítos en células parenterales de diversos tejidos, las cuales son de multiplicación "lenta o rápida" (Gállego, 2007). Los géneros más importantes desde el punto de vista sanitario en esta familia incluyen Toxoplasma, Neospora y Sarcocystis (Mehlhorn, 2008).

La toxoplasmosis es el resultado de la infección por el protozoario intracelular obligado Toxoplasma gondii (Miller et al., 1992; OIE, 2005). Este es un parásito ubicuo que posee además un amplio rango de hospedadores intermediarios (Hi) como el hombre y otros mamíferos, siendo reconocidos los felinos como los únicos hospedadores definitivos (Jubb, 2007). En animales infectados generalmente la enfermedad clínica ocurre en individuos jóvenes o inmunodeprimidos. Sin embargo, los marsupiales australianos, particularmente los macrópodos, han demostrado una mayor susceptibilidad a TX con altas morbimortalidades en adultos (Miller et al.; Bermúdez et al., 2009; Moré et al., 2010). El T. gondii tiene tres estadios infecciosos: los taquizoítos y bradizoítos que se encuentran en tejido nervioso, muscular (OIE; Jubb), bazo, hígado, ojo (Lopez, 2001) diafragma, estomago (Bermúdez, 2009) e intestino delgado (Bermúdez et al.; Moré et al.) tanto de hospedadores definitivos como intermediarios (OIE; Jubb) y los ooquistes que solo están presentes en las heces de hospedadores definitivos (OIE; Jubb). La transmisión es principalmente orofecal por el consumo de alimento o agua contaminada con ooquistes (Jubb).

El diagnóstico de TX está basado en la demostración microscópica de formas infecciosas en los tejidos (Canfield et al., 1990), ya que las lesiones macroscópicas a la necropsia, incluyendo edema, congestión (Bermúdez et al.) y consolidación pulmonar comúnmente no son especificas de la enfermedad (Canfield et al.; Jensen et al., 1985). Otras lesiones macroscópicas (observadas con menos frecuencia) incluyen hemorragias miocardicas, malacia cerebral difusa

\footnotetext{
* Universidad de los Llanos, Facultad de Ciencias Agropecuarias y Recursos Naturales, Escuela de Medicina Veterinaria y Zootecnia, Villavicencio, Meta Colombia.

** University of Wisconsin-Madison, Department of Pathobiological Sciences, Animal Health and Biomedical Sciences. Wisconsin (EUA).

**** Michigan State University, Diagnostic Center for Population and Animal Health, Michigan (EUA).
} 
o focal, ulceración gastrointestinal (Bermúdez et al.; Moré et al.), esplenomegalia y linfadenomegalia (Miller et al.; Jensen et al.; Patton et al., 1986). En macrópodos la muerte súbita sobreviene sin signos premonitorios (Miller et al.; Moré et al.) y las lesiones histológicas frecuentemente encontradas son necrosis como lesión predominante especialmente en el sistema nervioso central (SNC) (Moré et al.), pulmones, nódulos linfáticos, hígado o músculo y se presenta una respuesta inflamatoria variable (Moré et al.; Canfield et al.; Jensen et al.; Patton et al.; Garell, 1999). Los parásitos aparecen microscópicamente como pequeños quistes basofílicos (3 a $6 \mu \mathrm{m}$ ) que pueden ser encontrados libres en los tejidos afectados o dentro del citoplasma de muchas células epiteliales y macrófagos (López, 2001). Sin embargo, ninguno de estos cambios es específico de toxoplasmosis y otras pruebas diagnosticas específicas (Aker, 1992) como inmunohistoquímica con anticuerpos monoclonales o la reacción en cadena de la polimerasa, son necesarias para confirmar el diagnóstico de toxoplasmosis (Carlyle et al., 1997; Gutiérrez, 2000; Haziroglu et al., 2003).

En este reporte de caso se presenta una toxoplasmosis sistémica en un canguro rojo (Macropus rufus) mantenido en cautiverio donde se describen los hallazgos macro y microscópicos encontrados y los análisis adicionales realizados.

\section{MATERIAL Y MÉTODO}

Histotecnia. Las muestras de tejidos fijadas en formalina tamponada al $10 \%$ fueron procesadas mediante métodos rutinarios para microscopía óptica y los cortes histológicos de 3-4mm de grosor fueron teñidos con la coloración de Hematoxilina-Eosina (H\&E). En algunos cortes se realizó la tinción especial de Ácido Periódico Schiff (PAS).

Análisis inmunohistoquímico. Con el fin de confirmar el diagnóstico presuntivo de toxoplasmosis sistémica, fueron realizadas pruebas de inmunohistoquímica. La prueba fue llevada a cabo usando un antisuero policlonal antiToxoplasma gondii de cabra (210-70-TOXO, VMRD, Pullman, WA) a una dilución de 1:50.000. Adicionalmente se utilizó antisuero policlonal anti-Neospora caninum de cabra (210-70-NC, VMRD, Pullman, WA) en una dilución de 1:1000 para descartar que la infección fuese causada por este parasito. Para la inmunotinción de T. gondii, fue usado el sistema automático BenchMark de Ventana (Tucson, AZ) acompañado del V-Red kit mejorado para la detección del antígeno después de la recuperación del antígeno con el condicionador celular CC1 (Ventana). La inmunotinción del $N$. caninum fue llevada a cabo usando el autocolorador Bondmax (Leica, Bannockburn, IL), usando el acompañamiento del kit Define para la detección del antígeno, después de la recuperación del antígeno con la solución recuperadora de enlaces de epítopes 1 (Leica). Todas las laminillas fueron contratituladas con hematoxilina de Mayer. Los controles positivos consistieron de tejidos de un cachorro naturalmente infectado con $T$. gondii y de cultivos celulares infectados con N. caninum. Para los controles negativos los anticuerpos primarios fueron reemplazados con soluciones tamponadas. En adición, secciones de múltiples tejidos fijadas en formalina e incrustadas en parafina fueron analizadas mediante PCR para la detección de $T$. gondii and $N$. caninum.

Ensayos de reacción en cadena de polimerasa $(\mathrm{PCR})$ para Toxoplasma gondii. Dos ensayos separados fueron realizados para la detección de material genético de T. gondii por medio de la reacción en cadena de polimerasa (PCR), usando el ADN obtenido de secciones de tejidos infectados (corazón, hígado, bazo, páncreas, tráquea y cerebro) fijados en formalina e incrustados en parafina y cortados a $20 \mathrm{~mm}$ de grosor. Brevemente, la extracción y purificación del ADN total a partir de tejidos animales se realizó con el DNeasy® Blood \& Tissue Kit (Qiagen Inc, Valencia, CA) acorde al protocolo descrito por el fabricante y con mínimas modificaciones: los cortes de tejidos parafinados fueron lisados haciendo uso de $180 \mathrm{ml}$ de una solución ATL tamponada , y $20 \mathrm{ml}$ de proteinasa $\mathrm{K}$. El tubo fue incubado a $56^{\circ} \mathrm{C}$ hasta que la parafina se derritió y los tejidos fueron lisados. El tejido lisado fue retirado de la parafina derretida y ubicado en un nuevo tubo estéril $(0,5 \mathrm{ml})$. Todos los demás procedimientos fueron acorde a las instrucciones del fabricante. El ADN fue eluido con $50 \mathrm{ml}$ de una solución tamponada TAE.

En el primer ensayo de PCR la mezcla consistió de $2 \mathrm{ml}$ de ADN purificado, 12,5 ml de la enzima Amplitaq Gold (B PCR Master Mix (Applied Biosystems Inc., Foster City, CA), 9,9ml de agua de grado biológico, y 0,3 $\mathrm{ml}$ (25 pmolar por $\mathrm{ml}$ ) de cada cebador (Directo y Reverso). El par de cebadores utilizados fue descrito previamente por Bretagne et al. (1993), cebador directo 5'-ACGGGCGAGTAGCAC CTGAGGAGA-3' y cebador reverso 5'-TGGGTCTACG TCGATGGCATGACAAC-3', estos cebadores estaban dirigidos a la copia repetitiva número 35 del gen $\mathrm{B} 1$ de $\mathrm{T}$. gondii produciendo un amplicon o fragmento de 115-pb en tamaño. Las condiciones de la reacción para el primer ensayo de PCR fueron: desnaturalización y activación de la polimerasa 1 ciclo de $95^{\circ} \mathrm{C}$ durante $5 \mathrm{~min}$, desnaturalización 40 ciclos de $95^{\circ} \mathrm{C}$ durante 30 segundos, anidamiento $65^{\circ} \mathrm{C}$ durante 30 segundos, extensión $72^{\circ} \mathrm{C}$ durante 30 segundos; y una extensión final 1 ciclo de $72^{\circ} \mathrm{C}$ durante 5 minutos.

El Segundo ensayo de PCR para T. Gondii fue hecho para confirmar los resultados del primer ensayo. La mezcla reactiva para el segundo ensayo PCR consistía de $2 \mathrm{ml}$ de 
ADN, $12.5 \mathrm{ml}$ de enzima GoTaq ${ }^{\circledR}$ Green Master Mix (Promega Corporation, Madison, WI), 9,7 $\mathrm{ml}$ de agua de grado biológico molecular y $0,4 \mathrm{ml}(25$ pmolar por $\mathrm{ml})$ de cada cebador PCR (directo y reverso). Los cebadores usados fueron descritos previamente por Homan et al. (2000), cebador directo 5'-GACGCTTTCCTCGTGGTGAT-3' y cebador reverso 5'-CAGACACAGTGCATCTGGATTC-3' que estaban dirigidos para los plegamientos repetitivos 200 a 300 en una secuencia de 529 bp de ADN de T. gondii produciendo un fragmento o amplicon de 126bp en tamaño. Las condiciones de reacción para el segundo ensayo fueron 1 ciclo de $95^{\circ} \mathrm{C}$ por 5 minutos; 40 ciclos de $95^{\circ} \mathrm{C}$ por 30 segundos, $60^{\circ} \mathrm{C}$ por 30 segundos, $72^{\circ} \mathrm{C}$ por 30 segundos ; y 1 ciclo de $72^{\circ} \mathrm{C}$ por 5 minutos.

Para descartar la presencia de Neospora caninum se realizó un ensayo de PCR adicional. La mezcla reactiva consistía de 2ml AND extraido, 12,5ml de enzima Amplitaq Gold (B) PCR mezcla base (Applied Biosystems Inc., Foster City, CA), 9,7ml agua de grado molecular, y $0,4 \mathrm{ml}$ ( 25 pmolar por $\mathrm{ml}$ ) de cada cebador PCR (directo y reverso). Los cebadores usados fueron 5'-AATCAGCCTGCGTCAGGGTG-3' y 5'TCGTCCGCTTGCTCCCTATG-3'. Estos cebadores estaban dirigidos al gen Nc5 de $N$. caninum y producía una amplificación de un fragmento de 126-bp de tamaño. Los primeros fueron diseñados basándose en el reporte del gen Nc5 gene de N. caninum (N ascensión GenBank AY459289). Las condiciones de reacción para este ensayo de PCR fueron 1 ciclo de $95^{\circ} \mathrm{C}$ durante $5 \mathrm{~min} ; 40$ ciclos de $95^{\circ} \mathrm{C}$ durante $30 \mathrm{sec}, 65^{\circ} \mathrm{C}$ durante 30 segundos, $72^{\circ} \mathrm{C}$ durante 30 segundos; y un ciclo de $72^{\circ} \mathrm{C}$ durante 5 minutos.

Los productos de PCR fueron analizados por mediante electroforesis en gel de agarosa al 1,5\%, teñidos con bromuro de etidio y visualizados bajo luz UV.

\section{RESULTADOS}

El caso del animal estudiado correspondía a un canguro rojo (Macropus rufus) macho, de ocho años y $50 \mathrm{~kg}$ de peso corporal, que procedía de un circo y que rutinariamente era sometido a entrenamiento físico. La alimentación consistía en concentrado y frutas sin suplementación vitamínica o mineral. El animal murió súbitamente sin signos premonitorios y el veterinario a cargo realizó la necropsia y toma de muestras de tejidos, las cuales se remitieron al laboratorio de histopatología veterinaria de la Universidad de los Llanos.

Examen post mortem y resultados de necropsia. Hallazgos macroscópicos. Los principales hallazgos macroscópicos reportados por el veterinario fueron abscedación periapical premolar, enfermedad periodontal con necrosis y osteomielitis en maxilar superior; edema, congestión severa y cambios de coloración multilobular en pulmones; congestión en hígado junto con vesícula biliar pletórica; páncreas y bazo con irregularidades en el parénquima; sistema nervioso central con congestión severa y hemorragias focales.

Hallazgos microscópicos. Al análisis histopatológico bajo tinción de H\&E se diagnosticaron tanto en el hígado, como en el bazo respectivamente, una hepatitis necrótica multifocal con presencia de quistes de protozoarios con bradizoítos y una esplenitis supurativa fibrosa con metaplasia ósea asociada a quistes de protozoarios. En el Sistema Nervioso Central (SNC) se diagnostico una meningoencefalítis no supurativa necrótica asociada a quistes de protozoarios y fueron hallados en el miocardio múltiples bradizoítos e igualmente el páncreas también estuvo afectado por el parasitismo.

$\mathrm{Al}$ análisis histopatológico bajo tinción de PAS se revelaron bradizoítos y taquizoítos en los cortes histológicos de hígado, corazón, cerebro, páncreas y bazo.

Inmunohistoquímica. La detección de antígenos de $T$. gondii por el análisis inmunohistoquímico en los tejidos fijados en formalina se realizó usando un anticuerpo policlonal anti-Toxoplasma gondii, donde se confirmó la presencia del parásito en las secciones de tejidos teñidas (Figs. 1-3). La inmunoreactividad demostró la presencia de bradizoitos de Toxoplasma gondii, y de igual forma se evidencio la tinción de agregados antigénicos del parasito destruido.

Ensayos de reacción en cadena de polimerasa. La detección de $T$. gondii en los tejidos fijados en formalina fue hecha usando dos ensayos de PCR que estaban dirigidos hacia el ADN de diferentes secuencias repetitivas encontradas en el genoma de T. gondii. Los resultados para los ensayos de PCR demostraron que las bandas de los amplicones esperados alinearon en tamaño () con la banda del DNA del control positivo utilizado (Figs. 4 y 5). Asimismo el ensayo de PCR para N. caninum fue negativo (datos no mostrados).

\section{DISCUSIÓN}

La toxoplasmosis (TX) es una de las zoonosis más difundidas en el mundo y es una enfermedad que varía desde una infección inaparente hasta aguda fatal (Quinn, 1994). Los hallazgos histopatólogicos encontrados en el paciente, incluida la evidencia de taquizoítos, bradizoítos, además de la meningoencefalitis no supurativa y la hepatitis necrótica multifocal son algunas de las lesiones características que 


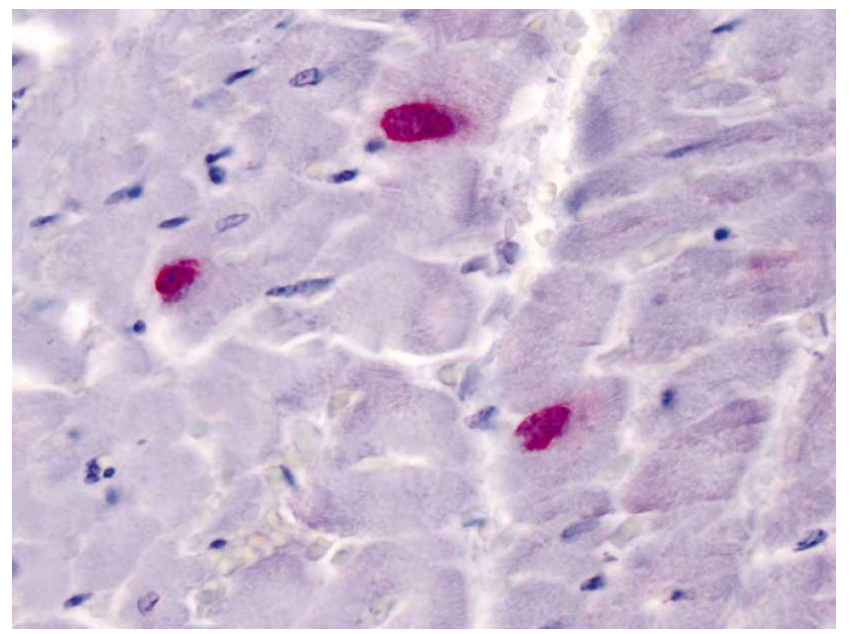

Fig. 1. Corazón, bradizoitos de T. gondii con inmunoreactividad, La reacción positiva es mostrada como color purpura fuerte (40x).

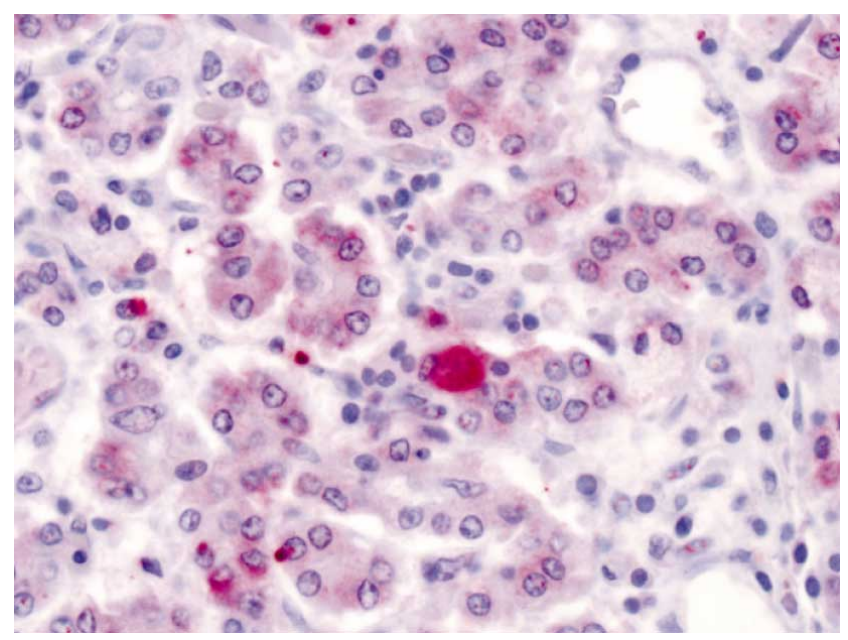

Fig. 2. Páncreas, bradizoitos de T. gondii con inmunoreactividad, La reacción positiva es mostrada como color purpura fuerte (40x).

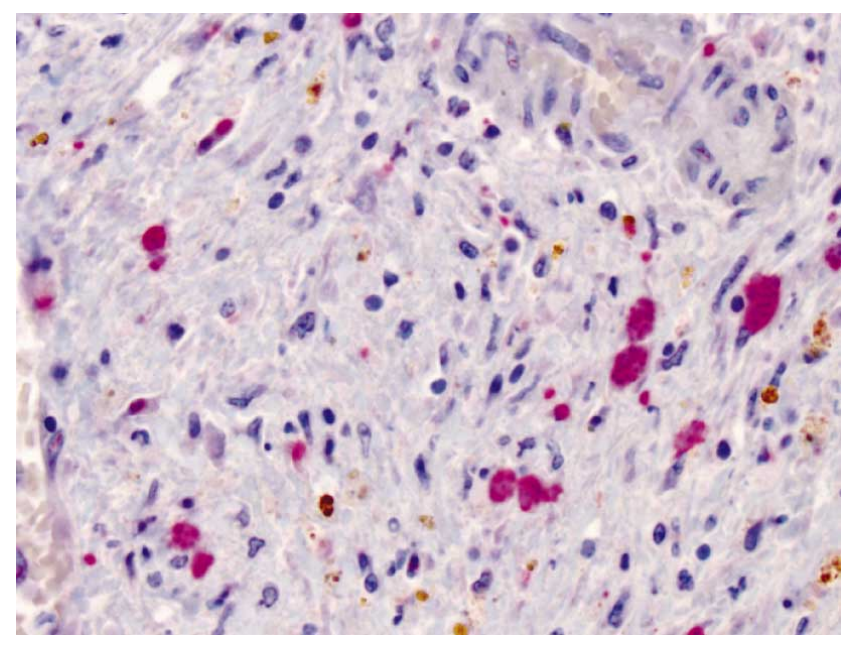

Fig. 3. Bazo con múltiples quistes (bradizoitos) de $T$. gondii con inmunoreactividad, La reacción positiva es mostrada como color purpura fuerte (40x).

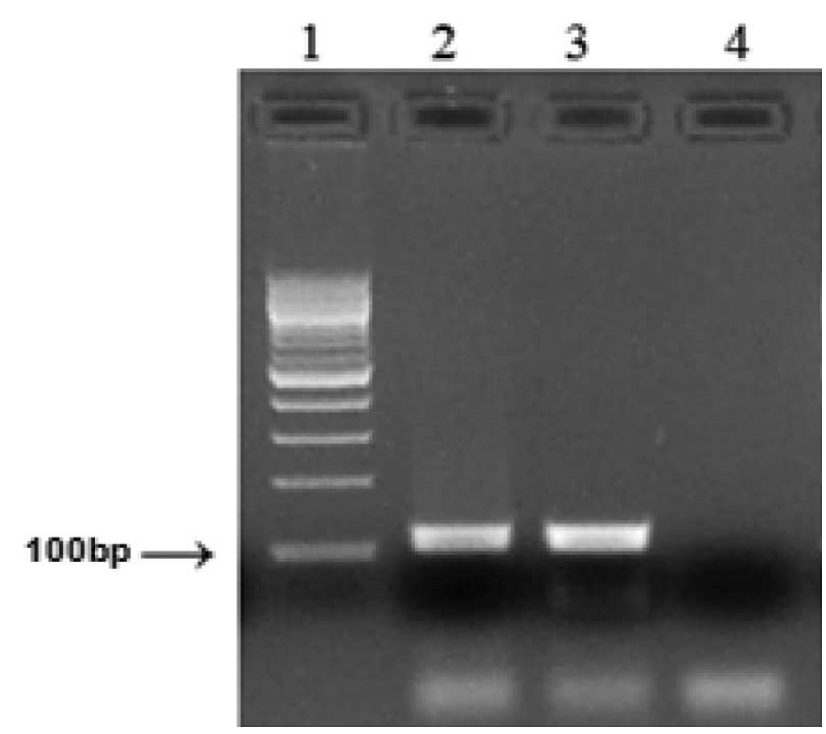

Fig. 4. Amplificación por PCR del ADN repetitivo de la región B1 encontrada en T. gondii. (1) Marcador de peso molecular, la flecha indica 100 pb. (2) Amplicon de 115-pb producido del ADN extraído de un pool de tejidos parafinados-formalinizados del caso de estudio. (3) Amplicon del ADN del control. (4) Control negativo, agua grado biología molecular.

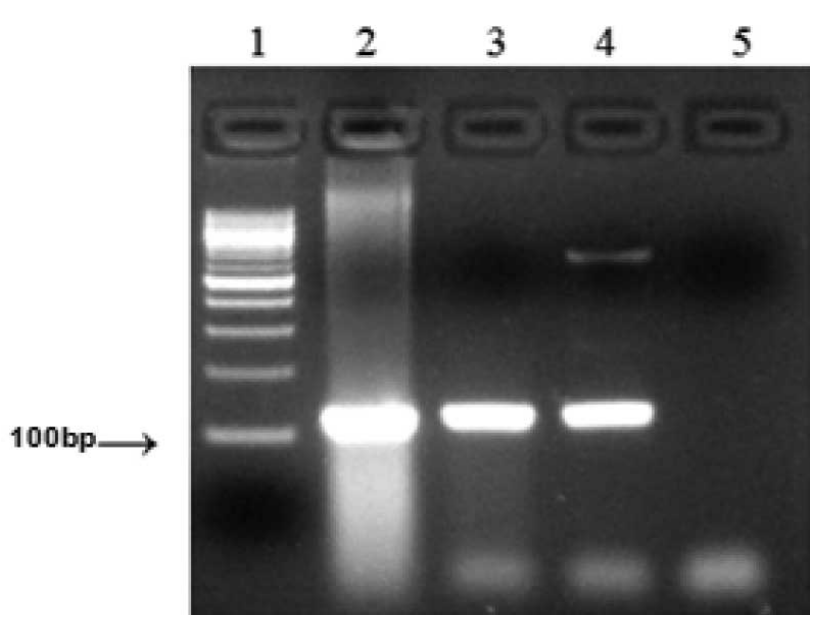

Fig. 5. Amplificación por PCR del ADN repetitivo de la región 529-pb encontrada en T. gondii. (1) Marcador de peso molecular, la flecha indica $100 \mathrm{pb}$. (2) Amplicon de 126-pb producido del ADN extraído de un pool de tejidos parafinados-formalinizados de un caso con diagnóstico sospechoso de toxoplasmosis no relacionado con este estudio (usado como control del procedimiento). (3) Amplicon de 126-pb producido del ADN extraído de un pool de tejidos parafinados-formalinizados del caso de estudio (4) Amplicon del ADN del control. (5) Control negativo, agua grado biología molecular.

han sido descritas en TX para macrópodos (Moré et al.; Lopez, 2001; Canfield et al.; Jensen et al.; Patton et al.; Garell; Montoya et al., 2000) lo cual sugiriere un diagnostico compatible con una infección crónica por Toxoplasma 
gondii en el animal estudiado. Sin embargo, es importante argumentar que el diagnóstico de infección por protozoarios eucoccideos de la familia Sarcocystidae basado solamente en la histopatología no llega a confirmar finalmente la etiología de la enfermedad (Carlyle et al.; Haziroglu et al.), debido a lo anterior, se realizaron pruebas complementarias específicas, entre estas la IHQ y la PCR, que permitieron la identificación efectiva del agente causal siendo este Toxoplasma gondii.

Ha sido descrito que $T$. gondii tiene capacidad de infectar numerosas especies, causando esporádicamente enfermedad en un amplio rango de animales tanto domésticos como silvestres (Bermúdez et al.; Tizard, 2002; Quiroz, 1996). El ciclo evolutivo de T. gondii es muy complejo y en animales herbívoros se ha sospechado que la principal ruta de transmisión del mismo es mediante el consumo de alimentos contaminados con ooquistes (Patton et al.). Para el caso particular se sugiere que al provenir de un circo, el animal se pudo infectar a través de material contaminado con ooquistes procedentes de las heces de gatos (Bermúdez et al.; Moré et al.; Montoya et al.), animales comúnmente encontrado en estos lugares.

La toxoplasmosis ha sido una de las enfermedades más comunes que afecta a los macrópodos australianos en condiciones de cautiverio (Montoya et al.) y ha sido reportada igualmente en muchos otros marsupiales bajo condiciones de cautiverio en diversos zoológicos del mundo (Bermúdez et al.; Moré et al.; Canfield et al.; Jensen et al.). Las lesiones invasivas de T. gondii en cerebro, corazón, bazo, hígado y páncreas descritas en el estudio coinciden con las referidas previamente por More et al. y Aker et al. para el caso de marsupiales experimentalmente infectados, sin embargo estas mismas corresponden con el reporte dado por Bermúdez et al. para el caso de marsupiales infectados en forma natural.

Los taquizoítos del parásito se multiplican en el interior de las células y cuando su número es excesivo rompen las células infectadas liberando las formas infecciosas o taquizoitos e invadiendo otras células por mecanismos similares a la fagocitosis. Cuando ellos invaden macrófagos normales no son destruidos puesto que bloquean la fusión fagosoma lisosoma, de modo que suprimen la producción de radicales tóxicos o citocinas y decrecen la inmunoreacción humoral y celular (Frenkel \& Escajadillo, 1987). Sin embargo, en fases crónicas los taquizoítos pueden transformarse en quistes tisulares conteniendo bradizoítos no inmunógenos y no estimulantes de la reacción inflamatoria (Frenkel \& Escajadillo; Frenkel, 1985). Cuando se produce desintegración de la membrana quística que recubre estos bradizoítos se desencadena una reacción de hipersensibili- dad inmunológica tipo IV que contribuye a la patogenia, pues causa necrosis tisular del tejido adyacente (Frenkel \& Escajadillo; Frenkel; Owen et al., 2004). Mientras que los taquizoítos se multiplican rápidamente y destruyen las células, los bradizoítos de multiplicación lenta coexisten con las células del hospedero por semanas incluso hasta años (Aker; Hoff \& Davis, 1986). En el paciente estudiado se observó la presencia múltiple de quistes conteniendo bradizoítos así como necrosis tisular en diferentes órganos, lo cual sugiere que el animal tenía una infección crónica con $T$. gondii en estados latentes que por algún detonante se reagudizo. No obstante, las infecciones latentes no se ven comúnmente en macrópodos debido a la alta tasa de mortalidad causado por esta enfermedad en estas especies (Bermúdez et al.). Probablemente en este paciente la infección se reactivó debido a múltiples situaciones que pudieron presentarse de forma aislada o a un mismo tiempo, entre estas cabe citar: el estrés inducido por el desplazamiento continuo del circo, y el estrés debido al mismo ambiente del circo, que incluye un ambiente ruidoso (Young \& Akill) y las condiciones del cautiverio (Terio et al., 2004). Una posible explicación para esta teoría dada podría ser que debido a la manipulación rutinaria y constante se provocó un estrés crónico por repetidas circunstancias estresoras que pudo llevar a una adaptación del organismo (Munson et al., 2005). Sin embargo, como es sabido, ciertas especies silvestres pueden mal adaptarse al estrés por cautiverio lo que resulta en una respuesta adrenocortical persistente (Wells et al., 2004). Se ha visto que muchos mamíferos silvestres cautivos sometidos a estrés crónico presentan lesiones hiperplásicas adrenales corticales y depleción linfoide esplénica (Jayo et al., 1993) coincidiendo este último reporte con los hallazgos encontrados en el canguro rojo estudiado. Aunque las respuestas individuales en los animales difieren en carácter, muchos presentan elevación significativa de los niveles basales de corticosteroides fecales que persisten por varios meses, particularmente en animales movidos de áreas de descanso hacia lugares de exhibición al público o que cambian frecuentemente de ubicación (Wells et al.), tal como sucede frecuentemente con los animales de circo. Del mismo modo se ha demostrado que los corticosteroides liberados en respuesta al estrés, promueven la lipogenesis (Jayo et al.), conllevando a lipomatosis hepática, sobre todo en animales que han sido sometidos a situaciones de estrés crónico (Munson et al.).

En conclusión, para este reporte de caso se evidenció histopatológicamente lesiones multiorgánicas atribuibles a una infección crónica por protozoarios eucoccideos de la familia Sarcocystidae confirmada por técnicas diagnosticas especificas, entre estas técnicas moleculares e inmunohistoquímicas que la etiología de la patología encontrada en este animal era un proceso concomitante con toxoplasmosis. 


\section{AGRADECIMIENTOS}

Muy especialmente a los doctores Francisco Uzal, Fabio Del Piero, Aniceto Méndez Sánchez, por su ayuda incondicional en la revisión y evaluación del articulo, al Doctor Matti Kiupel, Jefe del Laboratorio de Histología e Inmunohistoquímica del Centro Diagnóstico de Salud y Población Animal de la Universidad estatal de Michigan por la realización de las pruebas de IHQ.

OCHOA-AMAYA, J. E.; CIUODERIS-APONTE, K. A.; LIM, A.; BOLIN, S. \& LANGOHR, I. Systemic Toxoplamosis in a captive red kangaroo (Macropus rufus). Int. J. Morphol., 30(1):70-76, 2012.

SUMMARY: The objetives of this study were to present and document the hystopathologycal findings of systemic toxoplamosis in a captive red kangaroo (Macropus rufus) which described macro and microscopic findings of the hystopathological analysis. In the laboratory of animal histopathology (Universidad de los Llanos) formalin fixed tissue specimens were received, from a captive male Macropus rufus, who was eight years old and weighed $50 \mathrm{~kg}$. The samples were processed by usual methods for optical microscopy. The histological sections of 3-4 mm thick were colored with Hematoxilin-Eosin (H\&E) and then some samples stained with Periodic Acid Schiff (PAS), and processed by PCR and IHQ. Once the histopathological analysis was performed systemic toxoplasmosis was associated to protozoa cysts immunoreactives to $T$. gondii. The molecular detection of $T$. gondii in formalin fixed tissues was made using two PCR tests and confirmated by IHQ. Histopathologically a chronic infection by an eucoccideo protozoa from the Sarcocystidae family was diagnosed. The etiologic diagnosis was toxoplasmosis.

KEY WORDS: Kangaroo; Toxoplasmosis; Tachyzoites; Bradyzoites.

\section{REFERENCIAS BIBLIOGRÁFICAS}

Aker, H. The significance of histopathological diagnosis of toxoplasmosis (Experimental acute acquired toxoplasmosis in mice). Turk. Klin. Tip Bilim., 10:314-20, 1992.

Bermúdez, R.; Faílde, L. D.; Losada, A. P.; Nieto, J. M. \& Quiroga, M. I. Toxoplasmosis in Bennett's wallabies (Macropus rufogriseus) in Spain. Vet. Parasitol., 160:1558, 2009.

Bretagne, S.; Costa, J. M.; Vidaud, M.; Tran, J.; Nhieu, V. \& Fleury-Feith, J. Detection of Toxoplasma gondii by Competitive DNA Amplification of Bronchoalveolar Lavage Samples. J. Infect. Dis., 168:1585-8, 1993.

Canfield, P. J.; Hartley, W. J. \& Dubey, J. P. Lesions of toxoplasmosis in Australian marsupials. J. Comp. Pathol., 103:159-67, 1990.

Carlyle, T.; Hunt, R. D. \& King, N. W. Veterinary pathology. Diseases due to protozoa-Toxoplasmosis. ${ }^{\text {th }}$ Ed. Baltimore, Wiley-Blackwell, 1997. pp.560-1.

Frenkel, J. K. Toxoplasmosis. Pediatr. Clin. North Am., 32:91731, 1985.

Frenkel, J. K. \& Escajadillo, A. Cyst rupture as a pathogenic mechanism of toxoplasmic encephalitis. Am. J. Trop. Med. Hyg., 36:517-22, 1987.

Gállego, J. Manual de Parasitología: Morfología y biología de los parásitos de interés sanitario. 2 ed. Barcelona, Universitat Barcelona, 2007. pp.181-3.
Garell, D. M. Toxoplasmosis in zoo animals. In: Zoo and wild animal medicine, current therapy. Fowler, M. \& Miller, R. E. $4^{\text {th }}$ ed. Philadelphia, Saunders C.O., 1999. pp.131-5.

Gutierrez, Y. Tissue Apicomplexa. In: Diagnostic pathology of parasitic infections with clinical correlations. $2^{\text {nd }} E d$. New York, Oxford University Press, 2000. pp.223-8.

Haziroglu, R.; Altintas, K.; Atasever, A.; Gulbahar, M. \& Tunca, O. Pathological and Immunohistochemical Studies in Rabbits Experimentally Infected with Toxoplasma gondii. Turk. J. Vet. Anim. Sci., 27:285-93, 2003.

Hoff, G. L. \& Davis, J. W. Noninfectious diseases of wildlife. Iowa, The State University Press, 1982. pp.58-73.

Homan, W. L.; Vercammen, M.; De Braekeleer, J. \& Verschueren, H. Identification of a 200- to 300-fold repetitive 529 bp DNA fragment in Toxoplasma gondii, and its use for diagnostic and quantitative PCR. Int. J. Parasitol., 30:69-75, 2000.

Jayo, J. M.; Shively, C. A.; Kaplan, J. R. \& Manuck, S. B. Effects of exercise and stress on body fat distribution in male cynomologus monkeys. Int. J. Obstet. Metab. Dis., 17:597-604, 1993.

Jensen, J. M.; Patton, S.; Wright, B. G. \& Loeffler, D. G. Toxoplasmosis in marsupials in a zoological collection. J. Zoo. An. Med., 16(4):129-31, 1985.

Jubb, K. Inflammation in the central nervous system. En: Grant M.; Jubb, K \& Palmer's Pathology of Domestic Animals. 5th ed. Vol II. Philadelphia, Elsevier Saunders, 2007. p.437. 
Lopez, A. Respiratory System, Thoracic Cavity, and Pleura. In: McGavin, M. D.; Carlton, W. W. \& Zachary, J. F. Thomson's Special Veterinary Pathology. $3^{\text {rd }}$ ed. Philadelphia, Elsevier Saunders, 2001. p.185.

Mehlhorn, H. Encyclopedia of Parasitology. $3^{\text {rd }}$ ed. Berlin, Springer, 2008. pp.260-5.

Miller, M. A.; Ehlers, K.; Dubey, J. P. \& Van Steenbergh, K. Outbreak of toxoplasmosis in wallabies on an exotic animal farm. J. Vet. Diagn. Invest., 4:480-3, 1992.

Montoya, E.; Ique, C.; Samamé, H. \& Romaina, A. Seroprevalencia de Toxoplasma gondii en Aotus vociferans (Primates: Cebidae) en cautiverio. Rev. Cienc. Vet. Perú, 16(3-4):22-4, 2000.

Moré, G.; Pardini, L.; Basso, W.; Machuca, M.; Bacigalupe, D.; Villanueva, M. C.; Schares, G.; Venturini, M. C. \& Venturini, L. Toxoplasmosis and genotyping of Toxoplasma gondii in Macropus rufus and Macropus giganteus in Argentina. Vet. Parasitol., 169(1-2):57-61, 2010.

Munson, L.; Terio, K. A.; Worley, M.; Jago, M.; Bagot-Smith, A. \& Marker, L. Extrinsic factors significantly affect patterns of disease in free-ranging and captive cheetah (Acinonyx jubatus) populations. J. Wildl. Dis., 41:542-8, 2005.

OIE - Organización mundial de sanidad animal. Toxoplasmosis. Animal Disease Factsheets. The Center for Food Security \& Public Health. Ames, Iowa State University, 2005. pp.1-6.

Owen, M. A.; Swaisgood, R. R.; Czekala, N. M.; Steinman, K. \& Lindburg, D. G. Monitoring stress in captive giant pandas (Ailuropoda melanoleuca): behavioral and hormonal responses to ambient noise. Zoo. Biol., 23:147-64, 2004.

Patton, S.; Johnson, S. L.; Loeffler, D. G; Wright, B. G. \& Jensen, J. M. Epizootic of toxoplasmosis in Kangaroos, Wallabies, Potaroos: Possible transmission via domestic cats. J. An. Vet. Med. Assoc., 189:1166-9, 1986.

Quinn, P. J. Clinical veterinary microbiology. Dublin, Elsevier Health Sciences, 1994. p.463.

Quiroz, H. Parasitología y enfermedades parasitarias de animales domésticos. México D.F., Limusa, 1996. p 149.

Terio, K. A.; Marker, L. \& Munson, L. Evidence for chronic stress in captive but not freeranging cheetahs (Acinonyx jubatus) based on adrenal morphology and function. J. Wildl. Dis., 40:259-66, 2004.

Tizard, I. Inmunología veterinaria. $6^{\mathrm{a}}$ ed. México D.F., McGraw Hill Interamericana, 2002.

Wells, A.; Terio, K. A.; Ziccardi, M. H. \& Munson, L. The stress response to environmental change in captive cheetahs (Acinonyx jubatus). J. Zoo. Wildl. Med., 35:8-14, 2004.
Young, E. A. \& Akill, H. Corticotropin-releasing factor stimulation of adrenocorticotropin and $\mathrm{b}$ endorphin release: effects of accute and chronic stress. Endocrinology, 117:23-30, 1985.

\author{
Dirección para correspondencia: \\ Julieta Ochoa-Amaya \\ Universidad de los Llanos \\ Facultad de Ciencias Agropecuarias y Recursos Naturales \\ Escuela de Medicina Veterinaria y Zootecnia \\ Villavicencio, Meta \\ COLOMBIA
}

Email: julietaeochoa@yahoo.es

Recibido : 01-07-2011

Aceptado: 02-11-2011 